\title{
PENGEMBANGAN SISTEM SENSOR RASA BERBASIS MEMBRAN SELEKTIF ION UNTUK KLASIFIKASI BUAH JERUK
}

\author{
Bagas Surya Wibowo, Imam Tazi, Kuwat Triyana*) \\ Jurusan Fisika, Fakultas MIPA, Universitas Gadjah Mada, Yogyakarta \\ Sekip Utara BLS.21 Yogyakarta, 55281 \\ * ) e-mail: triyana@ugm.ac.id
}

\begin{abstract}
Abstrak - Sebuah sistem sensor rasa dengan sifat selektivitas global atau yang lebih dikenal sebagai lidah elektronik (etongue) berbasis pada larik sensor ion-selektif membran (ISMS)telah dibuat dan diterapkan untuk menganalisis secara kualitatif tiga macam buah jeruk (jeruk peras, jeruk siam dan jeruk nipis). E-tongue dilengkapi dengan sistem pengenal pola berbasis principle component analysis (PCA). Enam jenis lipid yang digunakan untuk membuat membrane selektif ion terdiri atas: asam oleat (OA), dioktil phosphat (DOP), desil alkohol (DA), dodesilamin (DDC), dan metil amonium klorida trioctyl (Toma). Setiap membran selanjutnya dipasang pada bagian dari tabung teflon yang memiliki lubang pada ujungnya, sehingga bagian dalam silinder terisolasi dari luar. Ujung tabung tersebut disegel dengan stopper yang memegang kawat Ag / AgCl. Sistem akuisisi data dalam e-nose dibangun menggunakan mikrokontroler. Agar dapat digunakan, tabung-tabung tersebut diisi dengan larutan KCl dengan konsentrasi 100 mM. Berdasarkan analisis PCA, e-hidung dapat mengklasifikasikan semua pola respon dari empat rasa dasar, yaitu, kepahitan (MgCl2), asin ( $\mathrm{NaCl}$ ), asam ( $\mathrm{HCl}$ ) dan kelezatan atau umami (MSG), ditunjukkan oleh nilai total komponen utama (PC1 dan PC2) sebesar 95,1\%. Selanjutnya, e-tongue juga mampu mengklasifikasi tiga jenis buah jeruk yang ditunjukkan oleh nilai total komponen utama sebesar 88,6\%. Dengan demikian, enose memiliki peluang sebagai alat untuk kendali mutu pada industri minuman berbahan buah jeruk.
\end{abstract}

Kata kunci : membran, lipid, rasa dasar, sensor rasa, buah jeruk

Abstract - A taste sensor system with global selectivity or electronic tongue (e-tongue) based on the sensor array of ionselective membranes (ISMs) combined with pattern recognition tools of principle component analysis (PCA) has been applied to qualitative analysis of citrus fruits (lemon, tangerine and lime). Six kinds of lipids were used for preparing the membranes; i.e., oleic acid (OA), dioctyl phosphat (DOP), decyl alcohol (DA), dodecylamin (DDC), and trioctyl methyl ammonium chloride (TOMA). Each membrane was fitted on part of a teflon tube which had a hole, such that the inner part of the cylinder is isolated from the outside. The end of the tube was sealed with a stopper that held an $\mathrm{Ag} / \mathrm{AgCl}$ wire. The e-nose was built including microcontroller based data acquisition system. The tube was filled with $100 \mathrm{mM} \mathrm{KCl}$ solution. Based on the PCA analysis, the e-nose is able to classify all the response patterns of four basic tastes, i.e., bitterness $\left(\mathrm{MgCl}_{2}\right)$, saltiness $(\mathrm{NaCl})$, sourness $(\mathrm{HCl})$ and deliciousness or umami (MSG), shown by the total PCs is $95.1 \%$. The e-nose is also able to classify the three kinds of citrus fruits shown by the total PCs is $88.6 \%$. Thus, the e-nose has opportunities as a tool for quality control in citrus-based beverage industries.

Keyword : membrane, lipid, taste sensor, basic taste, citrus fruit

\section{PENDAHULUAN}

Sistem sensor rasa atau yang juga dikenal dengan lidah elektronik (electronic tongue), yang selanjutnya disebut etongue merupakan sistem yang mempunyai selektivitas global. E-tongue dibangun atas larik sensor yang berbasis membran selektif ion. Setiap membran dibuat dengan mengkombinasi antara lipid dan polimer. Sifat selektif dari setiap membran sangat ditentukan oleh jenis lipid yang digunakan (Toko, 2000).

Aplikasi e-tongue sangat banyak, antara lain dalam bidang industri minuman dan makanan, lingkungan, dan farmasi. Pada bidang industri minuman, e-tongue diterapkan untuk mengetahui perubahan kualitas susu (Winquist, et al., 2005). Sementara pada bidang lingkungan e-tongue digunakan sebagai analisis kandungan air mineral (Moreno, et al., 2008), dan pada bidang farmasi, e-tongue dimanfaatkan untuk mengendalikan tingkat rasa pahit obat dan mengoptimasi tingkat rasa manis pada formula obat cair (Zheng dan Melissa, 2006).

Tidak ketinggalan, Laboratorium Fisika Material dan Instrumentasi FMIPA UGM juga telah mengembangkan etongue berbasis membrane selektif ion. Beberapa ujicoba harus dilakukan terhadap e-tongue yang dikembangkan untuk mengetahui potensi apliaksinya baik dalam hiding penelitian maupun industri (Kaltsum e al., 2009).

Makalah ini membahas mengenai pengembangan etongue menggunakan enam jenis elektroda berbasis membrane selektif ion dan aplikasinya untuk 
mengklasifikasi tiga jenis jeruk yang dibeli di pasar lokal Yogyakarta. Sistem akuisisi data otomatis pada e-tongue dibangun menggunakan mikrokontroler.

\section{LANDASAN TEORI}

Lidah elektronik atau sistem sensor rasa menurut Nystrom (2003) adalah sistem sensor yang digunakan untuk mengukur dan mengekstrak informasi dari larutan cair yang kompleks. Perbedaan antara sensor rasa dengan sensor biasa, seperti $\mathrm{pH}$-meter, adalah $\mathrm{pH}$-meter merupakan sensor selektif sedangkan sensor rasa merupakan sensor nonselektif. Sensor non-selektif bereaksi terhadap banyak stimulus berbeda yang dalam hal ini adalah zat kimia dan merespon sejumlah besar data, sehingga sensor rasa memiliki selektivitas global. Sensor ini juga disebut sensor cerdas karena mampu membedakan berbagai zat kimia meskipun dalam satu kelompok rasa.

Sistem sensor rasa menggunakan larik sensor rasa berupa membran selektif ion berbasis lipid. Output dari sistem ini berupa kualitas dan kuantitas rasa berdasarkan perbedaan pola potensial yang dihasilkan. Setiap membran akan memberikan respon potensial yang berbeda-beda terhadap suatu zat. Rasa didiskriminasi dan diklasifikasi berdasarkan gabungan pola potensial yang terbentuk dari larik sensor tersebut. Zat-zat yang memiliki rasa sama akan membentuk pola potensial yang sama, sedangkan zat-zat yang mempunyai rasa beda akan membentuk pola potensial yang berbeda pula.

Pada sensor rasa, membran yang digunakan adalah membran selektif ion yang respon terhadap ion-ion sampel yang berlawanan muatan dengan muatan membran. Membran ini dianggap sebagai permukaan datar dengan kerapatan muatan seragam. Perubahan kerapatan muatan permukaan disebabkan oleh interaksi antara bagian hidrofilik lipid membran dengan ion sampel uji. Perubahan kerapatan ini menimbulkan potensial membran yang kemudian dianalisa mewakili rasa tertentu.

Selektivitas sebuah membran didefinisikan sebagai kemampuan membran dalam merespon ion tertentu. Membran pada penelitian ini merupakan membran bermuatan listrik sehingga respon terhadap ion tertentu sampel. Membran akan respon terhadap ion sampel yang berlawanan dengan muatan membran. Membran OA, DOP, dan DA adalah membran negatif, sehingga akan respon terhadap kation sampel. Berbeda dengan membran DDC dan TOMA yang merupakan membran positif akan respon terhadap anion sampel.

Potensial membran $\left(E_{m}\right)$ tersusun atas potensial listrik permukaan $\left(E_{s}\right)$ yang terbentuk karena fase cair menyentuh membran ( $E_{\text {so }}$ untuk larutan sampel dan $E_{s i}$ untuk larutan internal) dan potensial difusi $\left(E_{d}\right)$ di dalam membran, seperti ditunjukkan dalam Persamaan (1).

$$
E_{m}=E_{s i}+E_{d}+E_{s o}
$$

Besarnya $E_{s i}$ adalah konstan karena larutan internal elektroda adalah tetap, sedangkan besarnya $E_{\text {so }}$ bergantung pada konsentrasi ion sampel uji. Secara ideal besarnya $E_{\text {so }}$ dirumuskan oleh Persamaan (2). Oleh karena itu, Persamaan (1) dapat dinyatakan menjadi Persamaan (3).

$$
\begin{aligned}
& E_{\text {so }}= \pm 2,303 \frac{R T}{z F} \log C \\
& E_{m}=E_{s i}+E_{d} \pm 2,303 \frac{R T}{z F} \log C
\end{aligned}
$$

dengan $R$ adalah konstanta gas Reydenberg (8,314 J/K mol), $T$ adalah suhu mutlak (K), $z$ adalah muatan ion sampel, $F$ adalah konstanta Faraday $\left(9,468 \times 10^{4} \mathrm{C} / \mathrm{mol}\right)$, dan C merupakan konsentrasi ion sampel. Tanda $(+)$ digunakan untuk ion sampel positif, sedangkan tanda (-) untuk ion sampel negatif.

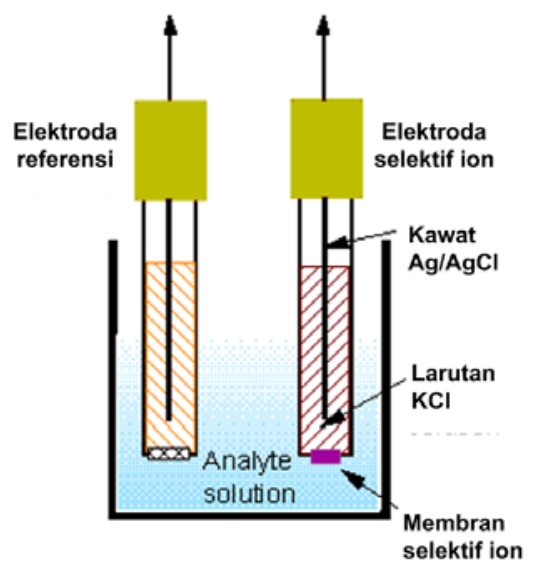

Gambar 1. Skema elektroda referensi dan elektroda kerja (elektroda selektif ion)

Elektroda kerja digunakan untuk mengukur nilai potensial dari sampel yang diuji. Elektroda kerja berupa pipa kecil sebagai badan elektroda yang didalamnya terdapat kawat Ag yang sebagian dilapisi dengan $\mathrm{Cl}$ atau $\mathrm{Ag} / \mathrm{AgCl}$. Badan elektroda memiliki rongga di dalamnya yang akan diisi dengan larutan $100 \mathrm{mM} \mathrm{KCl}$. Pada ujung pipa kecil elektroda ditutup menggunakan membran selektif ion. Skema elektroda referensi dan elektroda kerja (elektroda selektif ion) dilukiskan dalam Gambar 1.

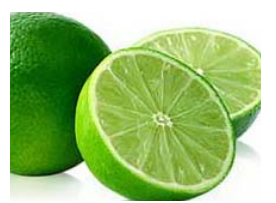

(a)

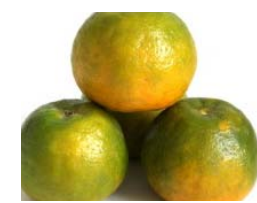

(b)

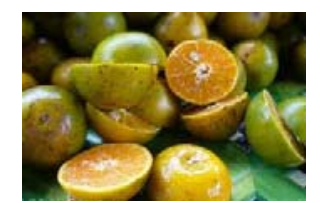

(c)
Gambar 2. (a) Jeruk nipis, (b) jeruk siam dan (c) jeruk peras

\section{METODE PENELITIAN}

Bahan yang digunakan dalam penelitian ini berupa bahan untuk membuat sampel dan membran seperti yang tertera pada Tabel 1. Membran merupakan sensor pada sensor rasa 
dengan komponen utama lipid, dioktil ptalat atau DOP sebagai plasticizer, matriks pendukung (PVC), dan THF sebagai pelarut. Lipid berfungsi menyaring ion-ion yang melewati membran, plasticizer melarutkan dan melenturkan membran, PVC mendukung membran agar lebih kuat, dan THF membantu mempercepat proses pengeringan membran.

Tabel 1. Bahan-bahan untuk membuat membran selektif ion

\begin{tabular}{ll}
\hline No & Bahan lipid \\
\hline 1 & OA \\
2 & TOMA \\
3 & DOP:TOMA $(5: 5)$ \\
4 & DA:OA $(5: 5)$ \\
5 & TOMA:DA $(5: 5)$ \\
6 & DDC. \\
\hline
\end{tabular}

Pengujian sensitivitas e-tongue diawali dengan pencucian membran menggunakan aquades. Pencucian dilakukan agar membran bebas dari residu zat lain. Proses pencucian membran dilakukan selama 5 menit. Penelitian dilakukan dengan memvariasikan konsentrasi larutan uji secara kontinyu. Konsentrasi larutan uji divariasikan secara bertahap dengan interval setiap 0,1 $\mathrm{M}$, yakni dari $0 \mathrm{M}-1 \mathrm{M}$. Untuk setiap variasi konsentrasi dilakukan pengukuran selama 5 menit.

Untuk mengaplikasikan e-tongue dalam membedakan larutan sampel jeruk, dilakukan pengukuran respon potensial terhadap tiga jenis jeruk, yaitu jeruk peras, jeruk nipis, dan jeruk siam. Pengukuran potensial dilakukan selama 5 menit agar didapatkan potensial yang stabil. Setiap sesi pengukuran dilakukan proses pencucian membran selama 3 menit.

\section{HASIL DAN PEMBAHASAN}

Sebelum diterapkan untuk menguji tiga jenis jeruk, etongue diuji terhadap tiga rasa dasar, yakni: sampel rasa asam, sampel rasa pahit, sampel rasa asin dan sampel rasa umami. Setiap rasa dasar diuji berulang sebanyak 3 kali di waktu yang berbeda. Respon potensial setiap sensor yang disajikan dalam radar plot disajikan dalam Gambar 3-5.

Secara visual dari Gambar 3-5 nampak jelas bahwa dengan pengulangan sebanyak tiga kali, daya ulang atau ripitibilitas e-tongue cukup baik. Perbedaan sedikit untuk elektroda tertentu kemungkinan disebabkan oleh masih adanya residu pada saat pencucian membrane. Selanjutnya pola-pola respon potensial e-tongue terhadap rasa dasar diolah menggunakan metode analisis statistik principle component analysis (PCA).

Gambar 6 adalah plot skor PC1 versus PC2 potensial respon e-tongue terhadap rasa dasar. Hasil PCA menunjukan bahwa keempat rasa dasar dapat diklasifikasikan kedalam rentang yang berbeda dengan persentase perbedaan PC1 sebesar 78,6 \% dan PC2 sebesar 16,5\%. Dari hasil yang didapat, diketahui bahwa e-tongue dapat membedakan empat rasa dasar dan memiliki sifat selektivitas global.

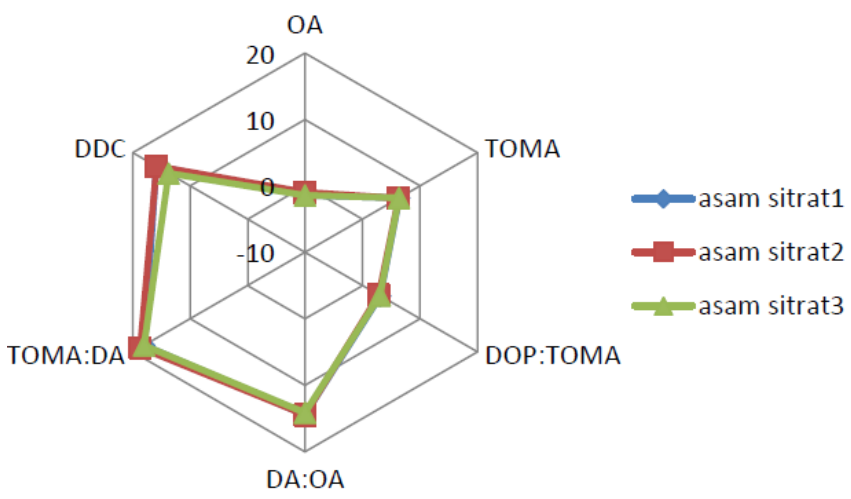

Gambar 3. Respon potensial e-tongue terhadap uji sensitifitas rasa asam (asam sitrat)
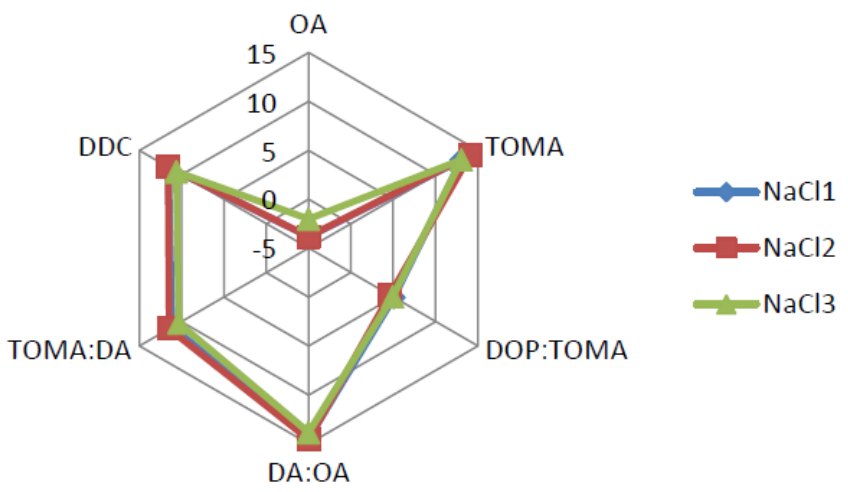

Gambar 4. Respon potensial e-tongue terhadap uji sensitifitas rasa asin $(\mathrm{NaCl})$

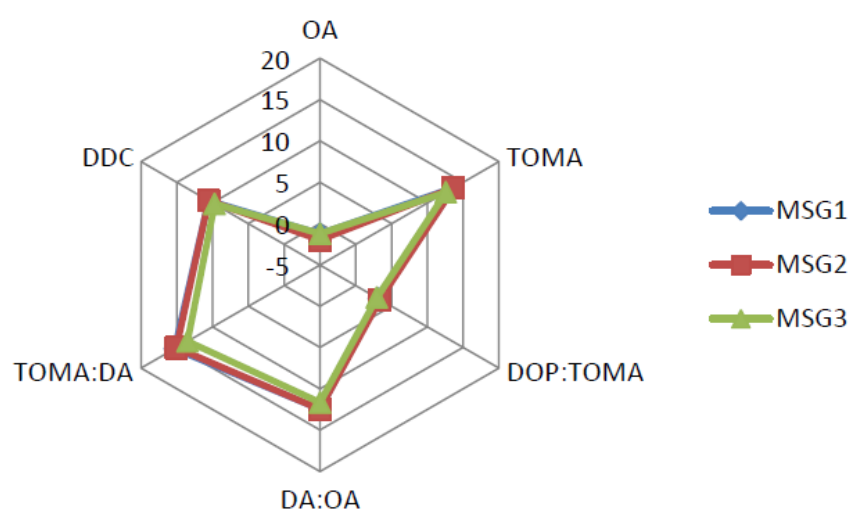

Gambar 5. Respon potensial e-tongue terhadap uji sensitifitas rasa umami (MSG)

Setelah terbukti bahwa e-tongue mampu membedakan keempat rasa dasar, maka selanjutnya diujikan terhadap tiga sampel jeruk, yakni jeruk peras, jeruk siam dan jeruk nipis. Seperti halnya dengan sampel rasa dasar, pengukuran rasa jeruk juga diulangi sebanyak empat kali untuk melihat daya ulangnya. Salah satu contoh pola respon e-tongue terhadap tiga jenis jeruk dilukiskan dalam Gambar 7. 


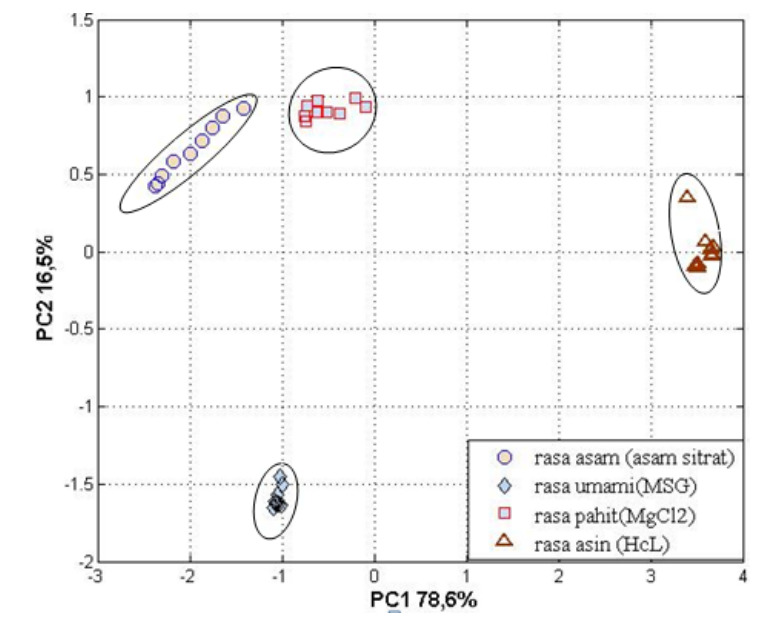

Gambar 6. Hasil analisis PCA untuk respon potensial e-tongue terhadap empat sampel rasa dasar

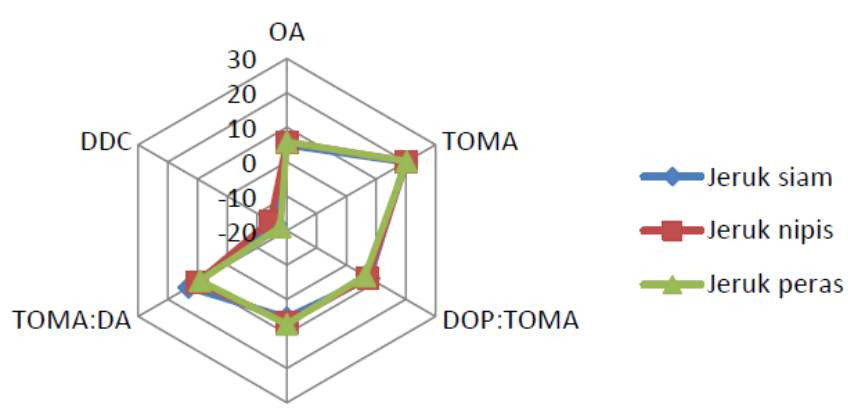

Gambar 7 pola potensial larutan jeruk

Secara sekilas, pola respon e-tongue terhadap ketiga sampel jeruk adalah mirip satu dengan yang lain. Namun dengan analisis PCA didapatkan hasil klasifikasi yang baik (Gambar 8). Berdasarkan pengolahan data menggunakan PCA diketahui bahwa nilai PC1 dapat membedakan rasa jeruk jenis yang berbeda dengan persentase perbedaan sebesar 68,4\%, sedangkan Pada PC2 dapat membedakan rasa jeruk dengan jenis berbeda hingga 20,2\%. Pengolahan data melalui PCA hanya ditampilkan 2 nilai PC, yaitu PC1 dan PC2 saja. Hal ini dikarenakan nilai dari PC3 hingga PC6 adalah sangat kecil jika dibandingkan dengan PC1 dan PC2, sehingga dapat dianggap tidak banyak berperan didalam membedakan masing-masing jenis jeruk. Jika nilai persentase PC1 dan PC2 dijumlahkan maka diperoleh sebesar 88,6\%. Ini berarti bahwa hasil persentase total PC1 dan PC2 adalah cukup tinggi, sehingga dapat dinyatakan bahwa e-tongue mampu membedakan rasa jeruk dengan jenis yang berbeda.

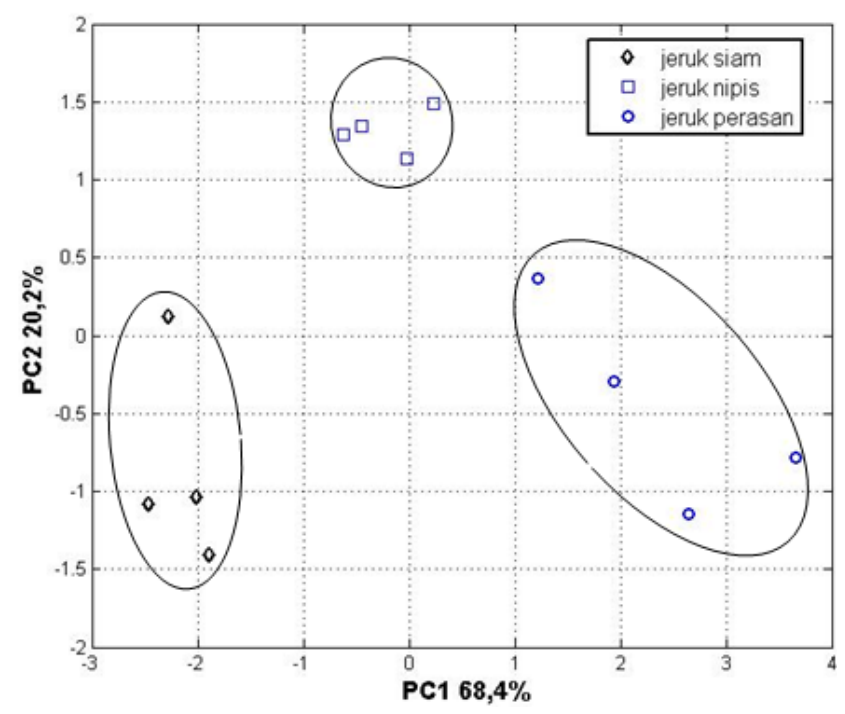

Gambar 8 Hasil analisis PCA pengukuran larutan jenis jeruk

Jeruk memiliki rasa campuran utama yakni rasa asam, rasa manis, dan rasa pahit. Rasa asam buah jeruh di dapatkan dari kandungan asam askorbat, dan asam sitrat. Rasa pahit pada sari buah jeruk disebabkan oleh kandungan senyawa naringin dan limonin. Rasa manis pada jeruk disebabkan oleh kandungnan glukosa, fruktosa, dan sukrosa. Setiap jeruk memiliki kandungan glukosa, fruktosa dan sukrosa dengan perbandingan 1:1:2. Kandungan gula akan meningkat dengan semakin matangnya buah (Andriani,2008). Namun sebagaimana kita ketahui bahwa rasa manis diwakili oleh molekul yang berjenis tidak polar. Dengan demikian maka perbedaan anta ketiganya oleh etongue lebih dominan diwakili oleh rasa selain manis.

\section{KESIMPULAN}

Secara umum, e-tongue yang dibuat berdasarkan enam membrane selektif ion telah menunjukkan kinerja yang sangat baik, yakni mampu mengklasifikasi empat rasa dasar. Lebi dari itu, e-tongue juga mampu membedakan rasa dari tiga macam sampel jeruk. Hal ini berarti bahwa e-nose yang dikembangkan ini mempunyai prospek untuk diterapka di industri yang bahan baku utamnya adalah jeruk.

\section{UCAPAN TERIMA KASIH}

Terima kasih penulis ucapkan kepada kelompok peneltian dari Lab Fisika Material dan Instrumentasi dan Prodi Elektronika dan Instrumentasi FMIPA UGM yang telah bekerja sama dalam mengembangan e-tongue. 


\section{PUSTAKA}

[1] K. Toko, Biomimetic Sensor Technology, Cambridge, University Press, United Kingdom, 2000.

[2] F. Winquist, R. Bjorklund, C. Krantz-Rulcker, I. Lundstroma, K. Stergren, dan T. Skoglund, An Electronic Tongue in the Dairy Industry, Sensors and Actuators B ,111112, 2005, 299-304.

[3] L. Moreno, A. Merlos, N. Abramova, C. Jim’enez, dan A. Bratov, Multi-Sensor Array Used as an "Electronic Tongue"for Mineral Water Analysis, Sensors dan Actuators B, 116, 2006, 130-134.
[4] J. Zheng, dan P. Melissa, Taste Masking Analysis in Pharmaceutical Formulation Development Using an Electronic Tongue, International Journal of Pharmaceutics, 310, 2006, 118-124.

[5] U. Kaltsum, U., K. Triyana dan D. Siswanta, Fabrication dan Characterization of Membrane Based on Taste Sensor to Classify Five Types of Basic Taste, Proc,ISSTEC 2009, 301.

[6] S. Nystrom, Evaluation of a New Method for Extraction of Drift-Stable Information from Electronic Tongue Measurements, Institutionen för Systemteknik, Linkoping, 2003.

[7] Andriani, Formulasi Sari Buah Jeruk Pontianak (citrus nobilis var. microcarpa) Dengan Aplikasi Metode LYE PEELING Sebagai Upaya Penghilangan Rasa Pahit Pada Sari Buah Jeruk, Skripsi, Departemen Teknologi Pangan dan Gizi, Institut Pertanian Bogor, Bogor, 2008. 